\section{God's gaze}

William R. Shea

Catching the Light: The Entwined History of Light and Mind. By Arthur Zajonc. Bantam: 1993. Pp. 388. $\$ 24.95, £ 16.99$.

WHAT is the nature of this invisible thing called light whose presence calls everything into view - except itself? Arthur Zajonc offers not a definitive answer but a fascinating account of what the question has meant over the ages. For the Ancient Egyptians, who sought a moral or spiritual answer, light was the gaze of God. For thinkers in the seventeenth century, who looked for a mechanistic account, it was explained by studying the geometry of refraction. In both cases, the quest was one-sided and, if this book has a moral, it is that we should read the full biography of light and not only the fragments that our own scientific community has written. Sight entails much more than just opening our eyes.

A few examples of colour vision among the Ancient Greeks and Romans convey some idea of the broad cultural and psychological basis of Zajonc's interdisciplinary study. Euripides writes in Iphigenia that blood made the side of the altar ksanthon. The word would therefore seem to mean red and Latin translators thus rendered it ruber. But Aeschylus in The Persians calls the leaves of the olive tree ksanthon, and in the lliad the term is used for honey. Other colours receive an equally perplexing treatment at the hands of the Greeks. Both the Moon and fiery eyes are glaukon, so it is natural to think of this word as referring to yellow or red. But Plato uses it for the mixture of dark blue and white, associating it with sky-blue or blue-grey - caesius, as the Latins rendered it - whereas Euripides uses it for a vestibule decorated with leaves, relating it to the colour of vegetation. Translators seek a way out by rendering glaukon as 'brilliant' or 'shiny'. For instance, "glaukopis Athene" becomes "flashing-eyed Athene" in the Loeb Classical Library. But this solution is itself highly problematic because the eye disease we call 'glaucoma' does not give the eye a shiny but a turbid appearance. Perhaps the Greeks were colourblind. But this radical solution is a counsel of despair. What is needed is not an eye doctor but a cultural anthropologist.

The Romans are closer to us and cannot be suspected of collective colour blindness. Those assuming that the English for purpureus is purple would find themselves in linguistic trouble when they discover that the poet Horace calls a swan purpureus. Indeed, the
Latins gave shiny black as well as shiny white objects the name purple. Or consider caeruleus, the word used to describe the sky, the sea and the eyes of Germans as well as the hair of Indians, the night and death! It is clear from these illustrations that a variety of different conceptual frameworks can be superimposed with equal validity on the order of 'coloured things'. The 'colours' that we encounter do not by themselves determine how we are to think of them independently of the apparatus of thought that we bring to the transaction.

Zajonc's catholic tastes and his rare gift of vivid characterization enable him to resurrect discarded images of vision such as the belief (shared by Plato, Euclid and even Galileo) that a visual ray emanating from the eye is essential for sight, or Aristotle's view that nothing streams from either eye or object but that illumination is a state or quality of the medium. Goethe's controversial ideas on colours are also displayed in their best light, and Rudolf Steiner's mystical musings on vision are examined against the interesting background of his quest for a science that would not belie genuine spiritual experience. The fundamental contributions of Faraday and Maxwell are lucidly described, and cur- rent research in quantum optics is given a provocative slant. We are reminded throughout that theories are aids to reflection and should never be hardened into permanent and disabling truths.

Catching the Light is a treasure-house of telling quotations and it is a pity that the generally useful references are sometimes incomplete. In a work that ranges so far and wide, it is understandable that a few mistakes should have slipped in. The Berlin suburb of Grunewald, which is mentioned, indeed celebrated, at least a couple of times, is provided with a gratuitous umlaut. Descartes did not write his Discourse on Method in 1619 but in 1636. It is misleading to suggest that he explained the rainbow in terms of white and black, and although he could have written "Give me motion and extension and I will construct the universe", it seems more ben trovato than ben documentato. These and other trivial errors could easily be corrected to make the second edition not only a vastly enjoyable and stimulating work but a truly reliable one as well.

William R. Shea is in the Centre for Medicine, Ethics and Law, McGill University, 3690 Peel Street, Montreal, Quebec H3A 1W9, Canada.

\title{
An essayist worth his saltations
}

\section{Bryan C. Clarke}

Elght Little Piggies: Reflections in Natural History. By Stephen Jay Gould. Norton/Jonathan Cape: 1993. Pp. 507. $\$ 22.95, £ 18.99$.

$\mathrm{OH}$ for J. B. S. Haldane's originality, Arthur Cain's encyclopaedic knowledge and Peter Medawar's skill in writing. Failing those, I would settle for Stephen Jay Gould's array of talents, perhaps with an added soupçon of modesty and rigour. As the old proverb says, "If wishes were butter-cakes, beggars might bite". But you do not need to be a millionaire to appreciate a good meal, and this is a feast.

When Gould began writing, his essays were spottily pretentious, showing too obviously that he was a very clever fellow, sometimes with humorous results when they misfired. Moreover, it was difficult to forgive him, in his early advocacy of 'punctuated equilibria', for doing less than justice to the ideas of Simpson and Mayr. Even then, though,

Cambridge University Press has recently published volume 8 of The Correspondence of Charles Darwin edited by F. Burkhardt, D. M. Porter, J. Browne and $M$. Richmond. The volume covers 1860 , a year dominated by the public and private response to the Origin of Species. $£ 40, \$ 59.95$. he was patently struggling to perfect his art, and he consistently improved.

Time has passed, and the ugly duckling has grown into a swan, still with some neotenic imperfections it is true, but a veritable swan. His latest collection is a lovely mixture of bizarre facts, nice arguments, clever insights into the workings of evolution and a quality of writing that can make your skin prickle. Surely enough there is a trick to it. You start with a small commonplace or oddity, weave it into an exemplar of some general principle, patch in a few quirky or informative asides and then come back to view the beginning from a new angle. It is a trick, but a difficult trick to do, and Gould does it supremely well.

Inevitably he is uneven. My own favourites are the chapters on vertebrates' jaws, ichthyosaurs' tails and the head-shields of cephalaspid fishes. He seems less secure in three essays based on the fossil fauna of the Cambrian period. The first, about meeting someone who knew Charles Walcott (the discoverer of the Burgess Shales), leaves an unpleasant taste because it seems to patronize a modest and respected scientist. The second and third concern the animals themselves. We learn that two puzzling 'shelly' fossils, Halkieria and 